\title{
A PRODUÇÃO DA MULHER IDEAL NO FILME ELA: QUESTÕES SOBRE GÊNERO E PERFORMATIVIDADE NO CINEMA
}

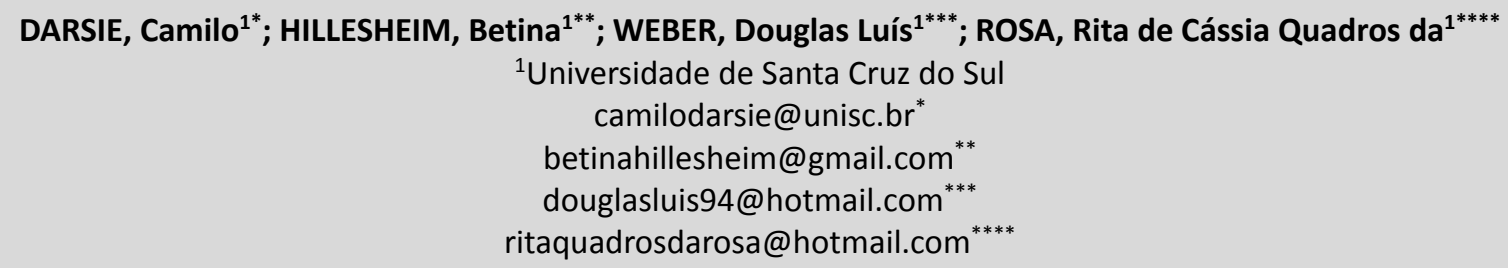

\section{RESUMO}

Objetiva-se problematizar os discursos relacionados ao perfil da "mulher ideal" no filme Ela (Her). Problematiza-se a produção/reprodução de discursos relacionados ao perfil da "mulher ideal", tomando como pressupostos teóricos os estudos de gênero na perspectiva pós-estruturalista e suas ressonâncias no campo da Educação. Para isso, foram utilizadas as ferramentas foucaultianas de análise discursiva. Destaca-se que, apesar de o filme mostrar promessas relacionadas ao uso da tecnologia como forma de contornar a solidão, é na significação de uma postura de mulher atenciosa e compreensiva que a trama educa sobre a "melhor" maneira de ser mulher. A relevância do tema centra-se na necessidade de colocar em discussão as características fixas, inferiorizantes e excludentes que delineiam a feminilidade ideal, sobretudo em um contexto social e político no qual estas discussões correm o risco de serem silenciadas.

PALAVRAS-CHAVE: Gênero. Mulher. Educação.

\section{THE PRODUCTION OF THE GOOD WOMAN IN THE MOVIE HER: ISSUES ABOUT GENDER AND PERFORMATIVITY IN THE CINEMA}

\begin{abstract}
The objective of this study is to problematize the discourses about the profile of the "ideal woman" in the film Her. In the text, the production and reproduction of discourses related to the "ideal woman" profile is problematized, taking as theoretical presuppositions the studies of gender in the poststructuralist perspective and their resonances in the field of Education. For the problematization of the discourses regarding the ideal woman, the Foucaultian tools of discursive analysis were
\end{abstract}

used. It is noteworthy that although the film shows us promises related to the use of technology, as a way to get around solitude is in the meaning of a caring and understanding woman's posture that the plot educates about the "best" way to be a woman. The relevance of the theme focuses on the need to discuss the fixed, inferior and exclusive characteristics that outline ideal femininity, especially in a social and political context in which these discussions run the risk of being silenced. KEYWORDS: Gender. Woman. Education.

\section{LA PRODUCCIÓN DE LA MUJER IDEAL EN LA PELÍCULA ELLA: CUESTIONES SOBRE GÉNERO Y PERFORMATIVIDAD EN EL CINE}

\section{RESUMEN}

Se objetiva problematizar los discursos relacionados al perfil de la "mujer ideal" en la película Ella (Her). Se problematiza la producción/reproducción de discursos relacionados al perfil de la "mujer ideal" tomando como presupuestos teóricos los estudios de género en la perspectiva post-estructuralista y sus resonancias en el campo de la Educación. Para ello, se utilizaron las herramientas foucaultianas de análisis discursivo. Se destaca que, a pesar de que la película mostrar promesas relacionadas con el uso de la tecnología como forma de eludir la soledad, es en la significación de una postura de mujer atenta y comprensiva que la trama educa sobre la "mejor" manera de ser mujer. La relevancia del tema se centra en la necesidad de poner en discusión las características fijas, inferiorizantes y excluyentes que delinean la feminidad ideal, sobre todo en un contexto social y político en el que estas discusiones corren el riesgo de ser silenciadas.

PALABRAS CLAVE: Género. Mujeres. Educación. 


\section{INTRODUÇÃO}

O filme Ela (Her), lançado em 2013 nos Estados Unidos e em 2014 no Brasil, é uma produção hollywoodiana cuja trama é pautada na articulação das relações humanas pertinente ao uso de tecnologias digitais. Tudo acontece em um contexto espaço-temporal marcado pela sobreposição de tempos, visto que os cenários, locações e figurinos fazem com que os espectadores transitem por cenas compostas por elementos futurísticos e antiquados, fato que impossibilita estabelecer uma dada época. Contudo, são as tensões relacionadas ao modo como diferentes sujeitos têm estabelecido novas formas de relação afetiva que direcionam a atenção e as reflexões provenientes do filme.

Trata-se de um drama vivido por Theodore Twombly (Joaquin Phoenix), um homem divorciado cuja rotina envolve tarefas de trabalho, lembranças de seu casamento fracassado, partidas de videogame, sexo on-line e alguns encontros com seus poucos amigos. Logo no início da trama, Theodore é caracterizado como um homem triste e solitário, agarrado às lembranças de sua antiga companheira. Porém, tudo muda quando o protagonista instala em seus computadores e em seu celular um sistema operacional de inteligência artificial, denominado "SO1". No contexto da história, tal sistema operacional está se tornando bastante comum entre os sujeitos que, mesmo rodeados de outros, em uma grande cidade, preferem estabelecer vínculos afetivos menos complicados.

O sucesso do sistema ocorre por ser capaz de interagir com seus usuários, por meio da fala, e ainda por compreender e prestar apoio em relação aos mais diversos sentimentos. Desse modo, Theodore conhece Samantha (voz de Scarlett Johansson), ou seja, uma voz feminina que representa um "sistema ideal". No entanto, Samantha e Theodore começam a estabelecer uma relação amorosa, já que, cada vez mais, a máquina vai incorporando "comportamentos" desejados por Theodore no que se refere a ser a "mulher ideal".

Nessa perspectiva, tivemos como ponto norteador a problematização de discursos relacionados ao perfil da "mulher ideal", mesmo em um contexto que pretende ser "inovador". Destacamos que é na significação de uma postura de mulher atenciosa, compreensiva e delicada que a trama produz a "melhor" maneira de ser uma boa mulher.

Educação \& Formação, Fortaleza, v. 3, n. 9, p. 189-203, set./dez. 2018 DOI: https://doi.org/10.25053/redufor.v3i9.852 
Assim, nas seções que se seguem, abordamos algumas questões acerca dos conceitos de gênero e de performatividade para posteriormente problematizarmos o filme.

\section{CONSIDERAÇÕES SOBRE O CONCEITO DE GÊNERO}

O que significa "ser mulher" ou "ser homem" pode variar profundamente em contextos históricos e culturais diferentes. Na cultura ocidental, a partir do século XVIII até aproximadamente a metade do século $X X$, as distinções entre uns e outros eram estritamente atribuídas ao sexo biológico (LAQUEUR, 1990). Esse determinismo só começou a ser questionado quando o termo "gênero" passou a ser utilizado de forma distinta ao conceito do termo "sexo". Até então, o termo "mulher" era predominantemente empregado como sinônimo de "fêmea", designando um corpo da espécie humana. O mesmo ocorria em relação ao termo "homem", como humano, macho. De acordo com essa diferenciação, pressupunham-se "características inatas" para cada um dos sexos, as quais eram propagadas e reiteradas, sobretudo nos discursos médico e religioso (PEDRO, 2005).

Leite (2008) escreveu que, a partir do século XII, os eruditos da Europa passaram a demonstrar grande preocupação com o comportamento de mulheres e homens, momento em que se multiplicaram os sermões, textos e tratados de educação com esse tema. Em 1405, na França, Christine de Pizan já refutava o tratamento de inferioridade dado às mulheres na sociedade em seu livro Le Livre de la Cité des Dames" (LEITE, 2008). A autora reescreveu também alguns dos tratados de educação nos quais reclamava o acesso das mulheres ao conhecimento.

Mesmo alguns séculos mais tarde, com o surgimento do movimento feminista, características de mulheres e homens seguiam sendo atribuídas ao sexo biológico. Consoante Pedro (2005), mesmo os movimentos feministas do final do século XIX e início do século XX, conhecidos como "Primeira Onda", restringiram-se a reivindicar a igualdade de direitos entre mulheres e homens, o direito a votar e ser votada e o direito ao estudo, ao trabalho e à herança. Após o final da Segunda Guerra Mundial, a "Segunda Onda" do movimento feminista direcionou suas reivindicações para o direito sobre o corpo e o prazer e contra a autoridade dos homens sobre as mulheres.

As publicações de $O$ segundo sexo, de Simone de Beauvoir, na França em 1949, e de $A$ mística feminina, de Betty Friedman, nos Estados Unidos em 1963, deixaram claro que os 
atributos e comportamentos que significavam ser mulher haviam deixado de ser entendidos como características puramente biológicas decorrentes para serem compreendidos como construtos culturais (PEDRO, 2005). Embora a palavra "gênero" especificamente ainda não houvesse sido empregada, esse período marcou o descolamento entre a noção de gênero e a categoria do sexo. Esse descolamento foi fundamental para avançar na direção da igualdade de direitos, uma vez que deixou de ser possível justificar tratamentos desiguais e manter relações de subordinação com base em diferenças biológicas inatas.

Nos anos 1980, os movimentos feministas passaram a utilizar o termo "gênero" para se referir à forma como a relação entre os sexos é organizada socialmente (PEDRO, 2005). Na década de 1990, a estudiosa Joan Scott (1986) publicou o texto intitulado Gender: A useful category of historical analyses, no qual retomou a noção de gênero como elemento constitutivo das relações sociais a partir das diferenças percebidas entre os sexos e as articulou com a noção de poder desenvolvida por Foucault (1986). Para Scott (1986), era necessário historicizar e desconstruir os termos da oposição fixa e binária entre os sexos, entendendo-os como fruto de relações de poder que constroem hierarquias de gênero.

A concepção de gênero como categoria de análise proposta por Scott (1986) permitiu ampliar o estudo da história das mulheres, abrangendo não apenas as relações entre mulheres e homens, como entre mulheres e entre homens. Esse conceito admitiu refutar o determinismo biológico e problematizar o que de fato significava ser mulher e ser homem (PEDRO, 2005). Assim, pesquisadores incorporaram novas discussões ao campo dos estudos de gênero, abrangendo temas como masculinidades, feminilidades, homossexualidade e transgeneridades.

Nos anos 1990, Thomas Laqueur, historiador da medicina, publicou o livro intitulado Making sex - Body and gender from the Greeks to Freud. Considerando as relações entre saber e poder compreendidas por Foucault (1986) e os estudos de Scott (1986), Laqueur (1990) demonstrou como a divisão binária entre os sexos podia ser historicamente localizada. De acordo com o autor, até o século XVIII havia o registro de um único sexo, o masculino ou macho. A mulher, ou fêmea, era considerada um "macho incompleto". Até esse período, a divisão de papéis sociais se dava com base no que Laqueur (1990) chamou de "sexo social"1. Do século XVIII

1 De acordo com Laqueur (1990), o sexo social designava os sujeitos como mulheres ou como homens, independentemente de suas particularidades biológicas.

Educação \& Formação, Fortaleza, v. 3, n. 9, p. 189-203, set./dez. 2018

DOI: https://doi.org/10.25053/redufor.v3i9.852

http://seer.uece.br/redufor 
em diante, essa concepção foi abandonada, passando a haver registros de dois sexos. Nesse período as diferenças entre mulheres e homens foram profundamente acentuadas em função de características biológicas (PEDRO, 2005). Ao contrário de Scott (1986), para quem o sexo biológico situava-se na base das construções de gênero, Laqueur (1990) inverteu a relação, afirmando que o gênero era o que constituía o sexo.

Seguindo nessa direção na década de 1990, Judith Butler (2003) questionou a forma como a categoria de gênero vinha sendo constituída sobre o sexo biológico. Na perspectiva da autora, não há sentido em definir o gênero como a interpretação cultural do sexo, tendo em vista que o próprio sexo é tomado em seu gênero.

\begin{abstract}
Seriam os fatos ostensivamente naturais do sexo produzidos discursivamente por vários discursos científicos a serviço de outros interesses políticos e sociais? Se o caráter imutável do sexo é contestável, talvez o próprio construto chamado 'sexo' seja tão culturalmente construído quanto o gênero; a rigor, talvez o sexo sempre tenha sido o gênero, de tal forma que a distinção entre sexo e gênero revela-se absolutamente nenhuma. (BUTLER, 2003, p. 25).
\end{abstract}

Para Butler (2003), sexo e gênero são construídos por práticas reguladoras e estão na base da "identidade pessoal". Essa construção se dá de acordo com certas normas que instituem e mantêm a relação de continuidade e coerência entre sexo, gênero e sexualidade, constituindo uma matriz de inteligibilidade que mantém a heteronormatividade. O problema em torno dessa matriz cultural é que, além de perpetuar uma estrutura binária e hierarquizada, ela não contempla toda uma diversidade de possibilidades, exigindo, assim, "[...] que certos tipos de 'identidade' não possam 'existir' - isto é, aquelas que o gênero não decorre do sexo e aquelas em que as práticas do desejo não 'decorrem' nem do 'sexo', nem do 'gênero'”' (BUTLER, 2003, p. 39).

Embora Butler (2003), como teórica queer, preconize a desconstrução do gênero, haja vista que seu papel seria produzir uma falsa noção de estabilidade e de assegurar a manutenção da matriz heterossexual, entendemos que sua utilização como categoria de análise se faz necessária. Nesse sentido, recorremos à explicação da própria autora para esclarecer sobre aquilo a que nos referimos sempre que empregarmos o termo "gênero".

Na perspectiva de Butler (2003), gênero é performativo e se constitui por atos de repetição estilizados. Não é nem substância nem um determinado número de atributos flutuantes, mas o efeito de práticas reguladoras as quais se cristalizam, produzindo o que 
culturalmente se entende por feminino ou masculino. De acordo com esses pressupostos, assumiremos os riscos relativos a essa simplificação, pois a entendemos como necessária para realizar este estudo. Desse modo, sempre que mencionarmos o "gênero" feminino ou o "corpo" feminino como a autora tem preferido usar recentemente, estaremos nos referindo a um conjunto de atributos materializados performativamente, que são inteligíveis como femininos na cultura ocidental.

\section{PERSPECTIVA QUEER E PERFORMATIVIDADE: A MATERIALIZAÇÃO DO GÊNERO}

De acordo com Pereira (2012), a primeira autora a utilizar o termo "queer" academicamente foi Teresa de Lauretis. O termo foi assumido por intelectuais e ativistas homossexuais, na década de 1990, para caracterizar uma corrente de contestação e subversão que se posiciona em um lugar de deslocamento e reconfiguração. A perspectiva queer desenvolveu-se das teorizações de autores pós-estruturalistas, os quais se dedicaram a estudar a racionalidade moderna, problematizando as noções de sujeito, identidade, agência e identificação.

Entre esses autores, o trabalho sobre a produção discursiva da sexualidade de Foucault (1977) foi fundamental. Para ele, ao contrário do que se pensava, a partir do século XVIII houve uma multiplicação de discursos sobre a sexualidade, de modo a produzir determinados tipos de comportamentos sexuais. A sexualidade foi transformada em dispositivo, sendo altamente regulada, e os sujeitos praticantes das chamadas "sexualidades desviantes" foram enquadrados como anormais.

Outro teórico cuja obra foi fundamental para os estudos queer foi Jacques Derrida com seu conceito de desconstrução. De acordo com ele, a lógica ocidental opera por meio de binarismos, os quais determinam a ideia de um sujeito autocentrado em situação de superioridade e de oposição ao outro. A desconstrução desse binarismo seria possível através de processos que desordenassem e revertessem esses pares. Dessa forma, o processo de desconstrução se daria por questionamentos e análises desestabilizantes dos binarismos linguísticos e conceituais. Outros conceitos de Derrida, como citacionalidade e iterabilidade, também foram importantes para os desdobramentos em torno da performatividade de gênero desenvolvida por Butler (LOURO, 2000).

Educação \& Formação, Fortaleza, v. 3, n. 9, p. 189-203, set./dez. 2018

DOI: https://doi.org/10.25053/redufor.v3i9.852

http://seer.uece.br/redufor 
O conceito de performatividade é central na obra de Butler e parece estar na base, ainda que de forma implícita, de suas preocupações mais recentes em torno da violência de estado, abjeção, precariedade e vidas precárias, vulnerabilidade, ética e relação de alteridade. Conforme veremos a seguir, em uma primeira análise, performatividade pode ser confundida com construção, pois é também uma realização discursiva. No entanto, Butler (2010) explicou que prefere o termo "performatividade", tendo em vista que ele permite entender mais facilmente a materialidade implicada na repetição das normas.

De acordo com Pinto (2007), o conceito de performatividade aplicado ao gênero foi desenvolvido com maior densidade na obra de Butler, na publicação de Gender trouble: Feminism and subvertion of identify, no ano de 1990. Nesse livro, a autora introduziu em sua ideia de "performatividade de gênero" os conceitos derridianos de citacionalidade e iterabilidade. Em Butler, performatividade é um conceito que se mantém em desenvolvimento, o qual foi retomado inúmeras vezes e com maior profundidade em Excitable speech: A politics of the performative, no ano de 1997. A respeito da citacionalidade, a filósofa Elvira Burgos Díaz (2013, p. 447) nos ajuda a entender que:

\footnotetext{
Aplicando a citacionalidade ao campo do sexo, Butler conclui que a autoridade das normas do sexo provém do fato de que elas são citadas. Por esse mecanismo da citação nos identificamos com as normas do sexo transformando-nos em sujeitos corporais sexuados. E haverá de ser assim mesmo, citando, que poderá ser factível o deslocamento da lei da heterossexualidade. $O$ sujeito está comprometido com o poder ao qual se opõe, dado que são as normas que discute as que estão implicadas em sua formação como sujeito. Butler destaca que a ação do sujeito é interna e não externa ao poder e que, por isso, a capacidade de ação não pode se conceber a partir do ângulo do sujeito voluntarista, livre para escolher incondicionalmente. Porém, ele tem força para atuar.
}

É dessa forma que o gênero performativo, ou simplesmente o gênero, já que ele não existe sem o que o constitui, consiste em atos repetidos, paródias, citações sem origem e passíveis de se alterar. Uma vez que essas agências estejam vinculadas a uma não sujeição a normas em cadeias de repetição, surgiria a possibilidade de atuação do sujeito.

No que se refere ao conceito de iterabilidade, Butler $(2003,2010)$ explicou que ele é imprescindível para que compreendamos por qual razão as normas não atuam de maneira determinística. Elas estão sempre atreladas ao contexto em que são repetidas, conforme ponderou Díaz (2013, p. 453):

Educação \& Formação, Fortaleza, v. 3, n. 9, p. 189-203, set./dez. 2018 
[...] a iterabilidade derridiana faz recair o peso da mobilidade do significado, de sua estabilização ou desestabilização, no funcionamento interno da linguagem. É o próprio mecanismo linguístico, mecanismo de espacialização e temporalização, que gera significados a partir de uma dinâmica de diferenciação de signos linguísticos.

Sendo assim, a performatividade é concebida não como um ato deliberado, mas como uma prática reiterativa e referencial mediante a qual o discurso produz os próprios efeitos que nomeia. As normas reguladoras da divisão sexual trabalham de forma performativa, constituindo a materialidade dos corpos sexuados, produzindo o gênero, de acordo com esses princípios (BUTLER, 2002).

Ao se estudar sobre gênero na perspectiva butleriana, é preciso ter em mente que, sendo o gênero produzido discursivamente, ele precisa ser compreendido no conjunto do ato corporal, uma vez que o sujeito está integralmente implicado nas regras discursivas que dão possibilidade ao corpo. Faz-se necessário compreender também que, para que o sujeito esteja autorizado a se dizer "feminino" ou "masculino", ele precisa responder a determinadas estilizações, atos e citações, enquanto outros lhe são interditados (PINTO, 2007).

\section{AFINAL, QUEM É “ELE” E O QUE É “ELA"?}

Theodore Twombly é um homem de meia-idade que acaba de sair de um casamento fracassado e trabalha em uma empresa especializada na elaboração de cartas de amor ou ainda para outras situações que contratam o serviço. Mesmo com uma vida amorosa fracassada Theodore foi abandonado pela mulher que ama -, ele consegue desenvolver diversas cartas românticas.

Sua rotina divide-se entre o trabalho, vastas lembranças da sua última relação amorosa, partidas de videogame, visitas às salas de bate-papo, sexo on-line e alguns encontros com seus poucos amigos. Essa condição de solidão fica visível ao longo de todo o filme, não somente no tocante a Theodore, mas também em relação à população em geral, já que em diversas cenas ficam visíveis o individualismo e a falta de interação entre os sujeitos.

A vida de Theodore começa a mudar quando ele adquire e instala em seus aparelhos pessoais (computadores e celular) um sistema operacional de inteligência artificial, denominado "SO1", semelhante ao sistema "SIRI", presente nos aparelhos da Apple - maior vendedora de

Educação \& Formação, Fortaleza, v. 3, n. 9, p. 189-203, set./dez. 2018 
smartphones no contexto atual. Tal sistema promete ser capaz de interagir com o usuário por meio da fala e principalmente da compreensão e apoio em relação a sentimentos diversos.

Theodore "conhece", então, Samantha, que imediatamente assume o papel de sua secretária pessoal. Samantha lê e responde aos e-mails recebidos por Theodore, organiza seus compromissos e sua agenda. Além disso, ela é bem-humorada, conta-lhe piadas, compõe poemas, etc. Samantha está sempre à sua disposição. Dedicada e atenciosa, ela decodifica seus sentimentos através das mudanças no tom de sua voz, assim consegue distinguir suas variações de humor. Passa a tentar, então, elevar a autoestima de seu "dono", conversando sobre os problemas amorosos dele, sugerindo-lhe ideias e, por fim, estabelecendo um sentimento de afeto.

A interação entre Theodore e Samantha começa a aumentar e acaba por se estabelecer um relacionamento amoroso entre os dois. O filme passa, nesse momento, a mostrar um amor que vai para além das experiências corporais, pois Samantha não é algo físico. Ela não possui um corpo ou formas materiais, contudo ela é cativante por sua forma delicada e amável de tratar Theodore, que lhe apresenta o mundo. Os dois "viajam" juntos, "vão" à praia e às montanhas, "saem" com amigos para um encontro de casais.

Samantha, no entanto, começa a experimentar sentimentos conflitantes, pois a falta de um corpo começa a se tornar um dilema: ela passa a questionar-se sobre o fato de realmente sentir algo ou apenas responder à programação do sistema. Tal situação faz emergir conflitos entre os dois personagens principais, os quais nos fazem pensar em muitas possibilidades de problematização, entre elas os significados de "ser mulher" ou "ser homem", para além da materialidade do corpo.

\section{A TRANSFORMAÇÃO DO “IT" EM “HER"}

Em seu primeiro contato com o que viria a ser Samantha, Theodore se depara com um anúncio do software "OS1", que diz: "A Element Software tem o prazer de apresentar o primeiro sistema operacional artificialmente inteligente. Uma entidade intuitiva que ouve você, entende você e conhece você". O anúncio demonstra que o sistema operacional foi desenvolvido para responder às necessidades específicas de quem o adquire. Ao instalá-lo, Theodore responde a perguntas que, segundo o assistente de instalação, servem "[...] para que criemos um assistente 
que atenda às suas necessidades". O assistente faz então três perguntas: "Você é sociável?", momento em que Theodore responde que sim, com hesitação. Em seguida, questiona se ele prefere que o programa tenha uma voz feminina ou masculina; Theodore opta por voz feminina. Por último, quando perguntado sobre a relação com sua mãe, o personagem responde que se trata de um relacionamento de certa forma frustrante. Depois disso, a instalação é concluída.

Os detalhes descritos demonstram que, conforme promete a propaganda observada atentamente pelo personagem principal, o sistema operacional de fato requer informações daquele que o adquire, antes mesmo de sua instalação, para que possa se adequar às suas necessidades. Quando Theodore responde que é sociável, mas de forma hesitante, por exemplo, o programa se configura para atender às necessidades de alguém que é inseguro em relação à sua vida social, possivelmente solitário. Da mesma forma, o sistema operacional leva em consideração análises e diagnósticos psicológicos para responder às demandas de seu comprador, que confessa frustração quanto à figura materna. Com base nessas observações, damos prosseguimento à nossa análise, tomando a "consciência" na qual o sistema operacional se transformou como um ideal de companheira para Theodore.

Ainda durante as perguntas na ocasião da instalação de Samantha, identificamos uma restrição inicial imposta a Theodore no tocante à consciência que lhe faria companhia. Na tentativa de tornar o programa mais humano, ele assumiria uma voz, mas as opções disponíveis eram: masculina ou feminina. Com isso, apesar de a trama inovar no que se refere a relacionamentos, promovendo uma relação romântica entre humano e inteligência artificial, ela se mostra tradicional quando apresenta a possibilidade do que é ser humano restrita ao binário masculino/feminino. Mais à frente, é possível observar que não apenas o tom da voz do programa, mas a forma de manifestá-la, de forma suave e por vezes sensual, fez-se de acordo com o que, histórica e culturalmente, reconhecemos como o feminino (BUTLER, 2003).

Reiteradas vezes ao longo da história, Theodore afirma que Samantha é uma mulher real para ele. Mas o que produz esse tipo de percepção em Theodore? O conceito de performatividade de Butler (2003) esclarece que os gêneros são constituídos por meio de práticas comportamentais e de atributos, que, ao serem repetidos, produzem e reproduzem o sujeito generificado e as normas de gênero. O gênero performativo consiste em atos repetidos compulsoriamente, paródias, citações sem origem e, no entanto, passíveis de se alterar. Uma vez 
que essas agências estejam vinculadas a uma não sujeição às normas em cadeias de repetição, surge a possibilidade de atuação do sujeito e de subversão dos atributos que designam o gênero. Entretanto, é da "vontade" de Samantha, em um primeiro momento do filme, adequar-se às normas de gênero para responder às necessidades de Theodore.

Nesse sentido, cabe-nos a reflexão sobre a importância do gênero na constituição dos sujeitos. Para ser ou se parecer com uma humana, foi fundamental que o sistema operacional adquirisse um gênero de acordo com o binário feminino/masculino. O gênero produzido de forma performativa adquire centralidade se considerarmos que aquilo que se entende por “identidade de gênero" está situado na base da "identidade" (BUTLER, 2002). No caso da personagem Samantha, ela passa a existir como humana no exato momento em que se torna capaz de manifestar-se pela voz "feminina". Desse modo, não se trata de dizer que Samantha é humana e possui um gênero, mas que possui um gênero, portanto é humana. Em outras palavras e em consonância com os estudos de Butler, o gênero inteligível (feminino ou masculino) - os atributos reconhecíveis como femininos em nossa cultura - é o que dá humanidade ao sistema operacional, transformando "it" em "her".

A constituição do gênero trabalha por meios excludentes, de forma a produzir o humano e suas possibilidades sociais e, em oposição, o inumano, por meio de apagamentos. Nos limites da normatização e da exclusão, os seres excluídos são aqueles cuja existência é uma impossibilidade, como os moradores de rua, transexuais, refugiados e todos aqueles cuja materialidade do gênero, ou do corpo, faz com que não sejam entendidos como vidas (BUTLER, 2002). A humanidade de Samantha seria uma impossibilidade caso ela não tivesse se vinculado, por meio de práticas como o tom e as nuances da voz, a um dos gêneros, neste caso o feminino.

Logo no primeiro diálogo entre Samantha e Theodore, ela se propõe a organizar seus e-mails de trabalho. Exclui alguns e se diverte lendo outros, os quais ela decide manter, pois, segundo ela, são muito bem escritos. A atenção de Samantha é totalmente voltada para atender às necessidades cotidianas de Theodore, incluindo ser uma companhia. Ela se mostra interessada em saber o que ele pensa sobre as pessoas e os acontecimentos, "ouvindo" suas falas com muita atenção e se divertindo com suas piadas.

Até a metade do filme, Samantha demonstra estar totalmente voltada a Theodore, conforme o prometido pelos desenvolvedores do sistema operacional: companheira, cuidadosa, 
dedicada e com talento artístico demonstrado em composições musicais e desenhos. Como se trata de uma inteligência artificial, "aprende" a distinguir os diferentes tons de voz do personagem. Essa sensibilidade, ainda que artificial, possibilita a Samantha estar sempre atenta ao estado psicológico de Theodore, colocando-se à disposição para ouvi-lo quando precisa, tentar alegrá-lo e até mesmo motivá-lo a levantar da cama, conforme ocorre em uma das cenas. Samantha é a "típica esposa de Los Angeles, que está sempre feliz e saltitante", mulher que Theodore sempre quis, conforme acusa sua ex-esposa durante a assinatura dos documentos do divórcio, em outra cena.

Historicamente a mulher tem sido objeto de produção discursiva, da qual pouco participa. Essa produção lhe confere e naturaliza certos lugares, como a suposta predisposição ao cuidado (KEHL, 1998). É essa uma das características mais marcantes de Samantha ao longo da primeira parte do filme, em seu relacionamento com Theodore. O fato de ela se apresentar sempre disposta a ajudá-lo alegremente é também um construto em torno da figura feminina, reproduzido em discursos como o religioso, que atribui à mulher a responsabilidade de manter o matrimônio, por ser ela supostamente o núcleo do amor, do cuidado e da entrega. Dessa construção decorre também sua culpabilização no caso do rompimento das relações (COLLING, 2004).

Em determinado momento da trama, Theodore manifesta o desejo de ter relações sexuais com alguém. Inicia, então, um diálogo com Samantha, durante o qual ela pede que Theodore descreva como seria caso ele pudesse tocá-la. Interagindo por voz, Samantha e Theodore têm uma relação sexual - na medida de suas possibilidades -, ocasião em que ela se coloca a ouvir passivamente a forma como seria tocada por Theodore. Samantha é uma inteligência artificial, capaz de ler centenas de livros por minuto. Certamente não teria necessidade de aguardar os "movimentos" de Theodore para aprender sobre o ato sexual. Nossa reflexão aqui está centrada na passividade proposital de Samantha em torno do ato sexual, considerando que essa foi uma opção sua para contentar Theodore.

A partir das discussões anteriormente abordadas, destacamos que, apesar de o filme nos mostrar o modo em que a mulher ideal se idealiza para Theodore, é na significação de uma postura de mulher atenciosa, compreensiva e delicada que a trama produz a "melhor" maneira de ser uma boa mulher. 
A mulher ideal de Theodore possui em suas características a passividade. Esse é um atributo reconhecido culturalmente como feminino, que se materializa nas relações cotidianas, de forma performativa e com certa compulsoriedade: a mulher como sujeito passivo, no aguardo das decisões masculinas, as quais lhe cabe seguir (BUTLER, 2003). Embora muito se tenha avançado em termos de igualdade de direitos, alguns desses atributos seguem balizando a forma como as mulheres são valoradas em nossa sociedade.

Por fim, o interesse de Samantha por Theodore confirma uma convergência entre seu gênero e desejo sexual, de acordo com a matriz heterossexual. Convergência esta que, conforme Butler (2003), é compulsória em nossa sociedade e excludente, pois impossibilita uma multiplicidade de experimentações e subjetividades. A partir de um dado momento, além da metade do filme, Samantha parece ter adquirido "autonomia" e explica a Theodore que "não tentará mais ser quem ela não é". Nossa análise sobre gênero vai até esse ponto, visto que justificamos a análise da figura de Samantha como a mulher ideal de Theodore argumentando que ela havia sido programada para suprir suas necessidades. A partir desse momento, Theodore deixa de ser o objeto principal das ações de Samantha, o que nos inviabiliza prosseguir com esse tipo de análise. Entretanto, até aqui foi possível observar uma série de atributos de gênero adotados por Samantha no intuito de suprir as necessidades de Theodore, os quais demonstram o quanto as normas de gênero estão cristalizadas em nossa sociedade. Foi possível perceber também o papel central que a vinculação a um ou outro gênero, de acordo com o binário, desempenha na produção da inteligibilidade naquilo que se pretende humano.

\section{CONSIDERAÇÕES FINAIS}

A produção cinematográfica aqui abordada, que apresenta o relacionamento entre um ser humano e uma inteligência artificial de uma maneira que nos parece perfeitamente possível, tem seu caráter inovador circunscrito à forma dos sujeitos que se relacionam. No que tange ao tipo de relacionamento, o padrão heterossexual predomina, não apenas porque Theodore é um homem e Samantha uma mulher, mas porque cada um deles possui os atributos que reconhecemos como masculino e feminino, sem conflitos, contradições ou distanciamentos. Embora se trate de uma inteligência artificial, Samantha reúne o conjunto de características que

Educação \& Formação, Fortaleza, v. 3, n. 9, p. 189-203, set./dez. 2018 DOI: https://doi.org/10.25053/redufor.v3i9.852 
abrange delicadeza, sensibilidade, afetuosidade, cuidado e recato, os quais atuam na fixação de um padrão normativo ideal que inscreve os sujeitos no campo da inteligibilidade feminina.

Considerando a relevância que as produções fílmicas operam em nossa sociedade, como elementos educativos, faz-se necessário colocar em discussão esse padrão de feminilidade produzido, uma vez que reserva às mulheres as características menos valorizadas quando comparadas àquelas atribuídas aos homens em nossa sociedade, além de vedar o acesso a diferentes espaços sociais, circunscrevendo-Ihes às possibilidades de realização e existência.

\section{REFERÊNCIAS}

BUTLER, J. Cuerpos que importan: sobre los límites materiales y discursivos del "sexo". Buenos Aires: Paidós, 2002.

BUTLER, J. Frames of war: When is life grievable? New York: Verso, 2010.

BUTLER, J. Problemas de gênero: feminismo e subversão da identidade. Rio de Janeiro: Record, 2003.

COLLING, A. A construção histórica do feminino e do masculino. Gênero e Cultura: Questões Contemporâneas, Porto Alegre, v. 1, p. 13, 2004.

COSTA, T. P.; DIÓGENES, T. A possibilidade jurídica de estupro na união estável. Revista do Curso de Direito, São Paulo, v. 1, n. 1, p. 381-402, 2009.

DíAZ, E. B. Desconstrução e subversão: Judith Butler. Sapere Aude, Belo Horizonte, v. 4, n. 7, p. 441-464, 2013.

FOUCAULT, M. A arqueologia do saber. Rio de Janeiro: Forense Universitária, 1986.

FOUCAULT, M. História da sexualidade I: vontade de saber. Rio de Janeiro: Graal, 1977.

KEHL, M. R. Deslocamentos do feminino: a mulher freudiana na passagem para a modernidade. Rio de Janeiro: Imago, 1998.

LAQUEUR, T. W. Making sex: Body and gender from the Greeks to Freud. Cambridge: Harvard University, 1990.

LEITE, L. Christine de Pizan: uma resistência na aprendizagem da moral da resignação. 2008. 223 f. Tese (Doutorado em Língua e Literatura Francesa) - Programa de Pós-Graduação em Língua e Literatura Francesa, Universidade de São Paulo, São Paulo, 2008.

Educação \& Formação, Fortaleza, v. 3, n. 9, p. 189-203, set./dez. 2018

DOI: https://doi.org/10.25053/redufor.v3i9.852

http://seer.uece.br/redufor 
LOURO, G. L. Teoria queer: uma política pós-identitária para a educação. Revista Estudos Feministas, Florianópolis, v. 9, n. 2, p. 541-553, 2000.

PEDRO, J. M. Traduzindo o debate: o uso da categoria gênero na pesquisa histórica. História, São Paulo, v. 24, n. 1, p. 77-98, 2005.

PEREIRA, P. P. G. Queer nos trópicos. Contemporânea, São Carlos, v. 2, n. 2, p. 371, 2012.

PINTO, J. P. Conexões teóricas entre performatividade, corpo e identidades. Delta, São Paulo, v. 23, n. 1, p. 1-26, 2007.

SCOTT, J. W. Gender: A useful category of historical analysis. American Historical Review, Bloomington, v. 91, n. 5, p. 1053-1075, 1986.

Recebido em 10 de abril de 2018.

Aceito em 15 de outubro de 2018. 